\title{
Receptividade do estigma e desenvolvimento do tubo polínico em flores de pessegueiro submetidas à temperatura elevada
}

\author{
Stigma receptivity and pollen tube development in peach flowers submitted to high temperature
}

\author{
Ilisandra Zanandrea ${ }^{\mathrm{I}}$ Maria do Carmo Bassols Raseira ${ }^{\mathrm{I}}{ }^{*}$ Juliano dos Santos $^{\mathrm{II}}$ \\ João Baptista da Silva ${ }^{\text {II }}$
}

\begin{abstract}
RESUMO
Dentre os diversos fatores que afetam a produtividade do pessegueiro em regiões subtropicais, está a ocorrência de temperaturas elevadas no início da floração. Tais temperaturas podem causar danos ao estigma e à germinação do grão de pólen, ocasionando decréscimo na fecundação e na fixação dos frutos. O presente trabalho teve por objetivo detectar diferenças entre genótipos quanto à tolerância à temperatura elevada $\left(29 \pm 2^{\circ} \mathrm{C}\right)$, bem como verificar se tais diferenças poderiam ser detectadas por um processo simples, utilizando ramos destacados. Para isso, foram realizados dois experimentos, sendo um com ramos destacados e outro com plantas inteiras em vasos, obtidas por enxertia, no outono. As estimativas de graus de receptividade do estigma e de comprimento do tubo polínico nos ramos destacados sugerem que as seleções Conserva 1566 e Conserva 693 e a cv. 'Maciel' não sofrem negativamente influência da temperatura de $29^{\circ} \mathrm{C}$. A receptividade do estigma, mesmo em ramos destacados, pode discriminar os genótipos quanto à tolerância da parte feminina a temperaturas próximas a $29^{\circ} \mathrm{C}$.
\end{abstract}

Palavras-chave: Prunus persica, pêssego, floração, abortamento floral.

\section{ABSTRACT}

Several factors can cause an erratic production of peaches under subtropical conditions. The occurrence of high temperatures on the beginning of blooming is one of them. Such temperatures can damage the stigma and the pollen germination, causing a decrease on fecundation and fruit set. The present work had the objective of looking for differences in tolerance to $29 \pm 2{ }^{\circ} \mathrm{C}$ among peach genotypes, as well as checking if a simple method using detached twigs would be suitable to detect differences. Two experiments were conducted using whole plants in vase, on one and detached twigs on the other. Estimates of pollen tube growth on the pistil and stigma receptivity suggested that selections Conserva 1566 and Conserva 693 and cv. 'Maciel' were tolerant to temperatures around $29^{\circ} \mathrm{C}$ at begining of blooming. Stigma receptivity, even in detached twigs, showed differences among genotypes.

Key words: Prunus persica, peach, flowering, floral abortion.

\section{INTRODUÇÃO}

O pessegueiro é uma das frutíferas de clima temperado que mais se estendeu às regiões subtropicais. Um dos fatores que determina a sua adaptação a essas áreas é a baixa necessidade de frio hibernal. Ao longo dos últimos anos, a maioria dos programas de melhoramento genético tem se dedicado a desenvolver cultivares com essa característica (RASEIRA \& NAKASU, 2002). Entretanto, nestas regiões, não é rara a ocorrência de altas temperaturas no início da floração, as quais podem resultar em baixa produtividade (KOZAI et al., 2004).

Alguns trabalhos, comparando genótipos com diferente tolerância ao estresse térmico, demonstram que muitas espécies são susceptíveis a altas temperaturas, particularmente na fase reprodutiva (PARK et al., 1998). Sabe-se que vários compostos

'Departamento de Botânica, Instituto de Biologia, Universidade Federal de Pelotas (UFPel), Campus Capão do Leão, Pelotas, RS, Brasil.

"Embrapa Clima Temperado, BR 392, Km 78, CP 403, 96010-971, Pelotas, RS, Brasil. E-mail: maria.bassols@cpact.embrapa.br. *Autor para correspondência.

IIIDepartamento de Física e Matemática, UFPel, Pelotas, RS, Brasil. 
orgânicos e inorgânicos interferem na germinação, contudo, existem outros fatores, como a temperatura, que influenciam significativamente na germinação e na viabilidade dos grãos de pólen, interferindo diretamente na fecundação dos óvulos e consequentemente na fixação dos frutos (RAMOS et al., 2008; CHAGAS et al., 2010).

Na região Sul e Sudeste do Brasil, alguns cultivos podem ser inviabilizados, principalmente em espécies como o pessegueiro, pois o processo de frutificação é altamente influenciável pelas condições climáticas, que podem contribuir para produzir frutificações erráticas. Diante disso, os objetivos do trabalho foram identificar genótipos de pessegueiro tolerantes à temperatura de $29 \pm 2^{\circ} \mathrm{C}$ no período de floração e comparar os resultados obtidos por um método simples de ramos destacados com aqueles obtidos com plantas inteiras em vasos.

\section{MATERIAL E MÉTODOS}

Para estudar a receptividade do estigma e a elongação do tubo polínico, foram realizados dois experimentos distintos e verificada a possível correlação entre os resultados.

Ramos destacados: foram coletados, em pomar da Embrapa Clima Temperado, ramos com flores em estádio de balão, das cultivares 'Atenas' ('Alpes' $\mathrm{x}$ 'RR53272') Pl (polinização livre), 'Maciel' ('Conserva 171' x 'Conserva 334', sendo cons. 171 ='Aldrighi' x 'Pelotas 76') e 'Granada' ('Alpes' x 'Conserva 102') Pl, e das seleções 'Conserva 1054' ('Maciel' x ‘Conserva 696'), 'Conserva 1187' ('Conserva 594' x 'Granada'), 'Conserva 1566' ('Esmeralda' (='Alpes' (= 'Aldrighi' x 'Tapes') x 'RR 37.201') x 'Conserva 594'), 'Conserva 1186' ('Granada' x 'Conserva 708'), 'Conserva 1218' ('Conserva 672' x 'Maciel') e 'Conserva 693' ('Precocinho' x 'Conserva 334'). Os ramos, coletados nos meses de Julho e Agosto de 2010, foram colocados em vasos de vidro contendo $100 \mathrm{~mL}$ água, de modo que a base ficasse submersa. Os botões florais foram emasculados imediatamente. Metade dos ramos foi levada para o fitotron a $29 \pm 2^{\circ} \mathrm{C}$ e metade foi colocada em temperatura ambiente (controle, $\leq 20^{\circ} \mathrm{C}$ ).

Plantas enxertadas: ramos de duas cultivares de pessegueiro, 'Granada' e 'Maciel' e da seleção Conserva 693 foram coletados de plantas, em produção, em pomar comercial na região de Pelotas-RS, e enxertados por garfagem de fenda cheia, segundo metodologia descrita por HERTER et al. (2004), em seedlings da cultivar 'Aldrighi'. Esses haviam sido previamente plantados em recipientes (5 litros), contendo uma mistura de solo + areia (2:1) como substrato. Após a enxertia, as plantas permaneceram em telado durante 30 dias para formar a união entre enxerto e porta-enxerto. Decorrido esse tempo, plantas de cada uma das duas cvs. e da seleção, com gemas florais em estádio de balão, foram emasculadas, parte foi colocada em temperatura ambiente $\left(\leq 20^{\circ} \mathrm{C}\right)$ e parte foi levada para o fitotron $\left(29^{\circ} \mathrm{C}\right)$.

Em ambos os experimentos, dez flores, por repetição, foram polinizadas nos tempos zero, $24,48 \mathrm{e}$ 72 horas após a emasculação. Para a polinização, foi utilizado sempre o mesmo pólen (Conserva 693, com viabilidade de 58\%). Passadas 24 horas após a polinização, os pistilos foram coletados e colocados em frascos contendo fixativo FAA (formol, ácido acético e álcool etílico 1:1:8) e armazenados em geladeira $\left(4^{\circ} \mathrm{C}\right)$. Para a observação do número de grãos de pólen aderidos ao estigma e a percentagem de grãos de pólen germinados, foi utilizado o método descrito por WILSON \& BROWN (1957), adaptado para frutíferas (CARVALHO \& RASEIRA, 1989). A montagem da lâmina foi feita com Lacmóide diluído duas vezes e a visualização dos pistilos, em microscópio óptico com ocular de 10x e objetiva de 40x.

A receptividade do estigma foi estimada conferindo graus, conforme as seguintes classes: 0 - nenhum grão de pólen germinado no estigma; 1 muito poucos (1 a 5); 2- poucos (6 a 10); 3- médio (de 11 a 15) e 4- muitos (acima de 16). Os dados foram transformados em $\log (x+1)$.

Para o alongamento do tubo polínico no interior do pistilo, também foram conferidos graus segundo a escala de FRANKEN et al. (1988), modificada, considerando-se sete classes, sendo: grau $0=$ sem pólen no estigma; 1 = germinado no estigma; 2 = entre estigma $\mathrm{e}^{1 / 4} ; 3=$ entre $^{1 / 4} \mathrm{e}^{1 / 2} ; 4=$ entre $1 / 2$ e entrada do ovário; 5 $=$ na entrada do ovário; $6=$ no ovário; $7=$ no óvulo. Os dados foram transformados em $\log (x+1)$.

$\mathrm{O}$ delineamento experimental foi completamente casualizado, com três repetições e 10 flores por parcela. Foi calculada a correlação entre os dados dos três genótipos comuns aos dois experimentos.

\section{RESULTADOS E DISCUSSÃO}

Quando foram utilizados ramos destacados, houve interação significativa $(\alpha=0,05)$ entre cultivar e temperatura, cultivar e tempo e tempo e temperatura para a variável elongação do tubo polínico. $\mathrm{O}$ aumento da temperatura influenciou negativamente na elongação do tubo polínico na cultivar 'Atenas' e na seleção Conserva 1218. Estas apresentaram tubo polínico $14 \%$ e $13 \%$ menores, respectivamente, quando submetidos a $29^{\circ} \mathrm{C}$. Já para a seleção Conserva 1054 , houve um efeito oposto, sendo o comprimento do tubo polínico $21 \%$ maior a $29^{\circ} \mathrm{C}$ do que a $20^{\circ} \mathrm{C}$. Não houve diferença para os demais genótipos (Tabela 1). 
Tabela 1 - Elongação do tubo polínico em flores de ramos destacados de pessegueiro submetidos a $20^{\circ} \mathrm{C}$ e $29^{\circ} \mathrm{C}$. Embrapa Clima Temperado, Pelotas, 2010

\begin{tabular}{llllllllll}
\hline $\mathrm{T}\left({ }^{\circ} \mathrm{C}\right)$ & 1054 & $1187^{\mathrm{NS}}$ & $1566^{\mathrm{NS}}$ & $1186^{\mathrm{NS}}$ & 1218 & $\mathrm{C}^{\mathrm{NS}} 3^{\mathrm{NS}}$ & Atenas & Maciel $^{\mathrm{NS}}$ & Granada $^{\mathrm{NS}}$ \\
\hline 20 & $0,96 \mathrm{~b}$ & $1,13 \mathrm{ab}$ & $1,23 \mathrm{a}$ & $1,03 \mathrm{ab}$ & $1,03 \mathrm{ab}$ & $1,14 \mathrm{ab}$ & $1,12 \mathrm{ab}$ & $1,04 \mathrm{ab}$ & $1,16 \mathrm{a}$ \\
29 & $1,16 \mathrm{abc}$ & $1,18 \mathrm{a}$ & $1,20 \mathrm{a}$ & $0,98 \mathrm{bcd}$ & $0,90 \mathrm{~d}$ & $1,18 \mathrm{ab}$ & $0,96 \mathrm{~cd}$ & $1,10 \mathrm{abc}$ & $1,03 \mathrm{abcd}$
\end{tabular}

Médias seguidas pela mesma letra minúscula nas linhas não diferem entre si pelo teste de Tukey $(\alpha=0,05)$. NS: Não significativo pelo teste de $\mathrm{F}(\mathrm{P}>0,05)$.

Sob temperatura de $20^{\circ} \mathrm{C}$, a maior elongação do tubo polínico foi verificada quando a polinização foi realizada 48h após a emasculação(1,41 grau)(Figura 1). Já a $29^{\circ} \mathrm{C}$, houve uma maior elongação do tubo polínico quando a polinização ocorreu 24h após a emasculação (1,48 grau). A análise de regressão aponta que nesta temperatura o melhor desenvolvimento do tubo polínico deve ocorrer quando a flor é polinizada $30 \mathrm{~h}$
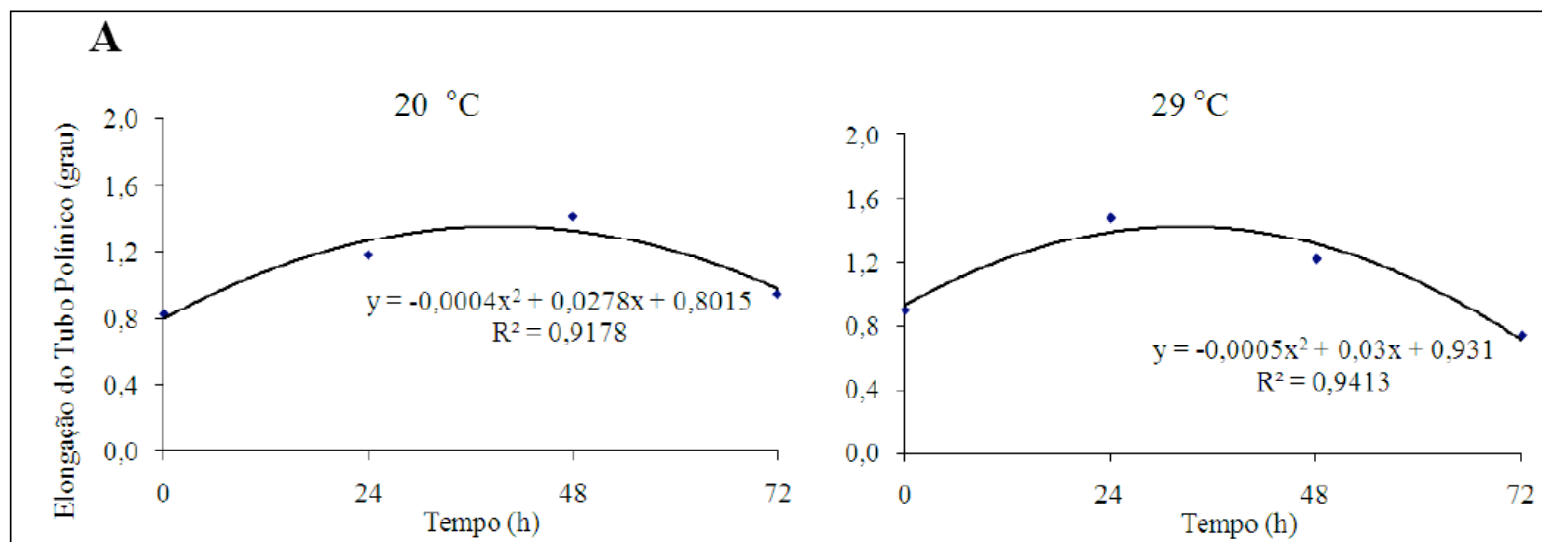

B
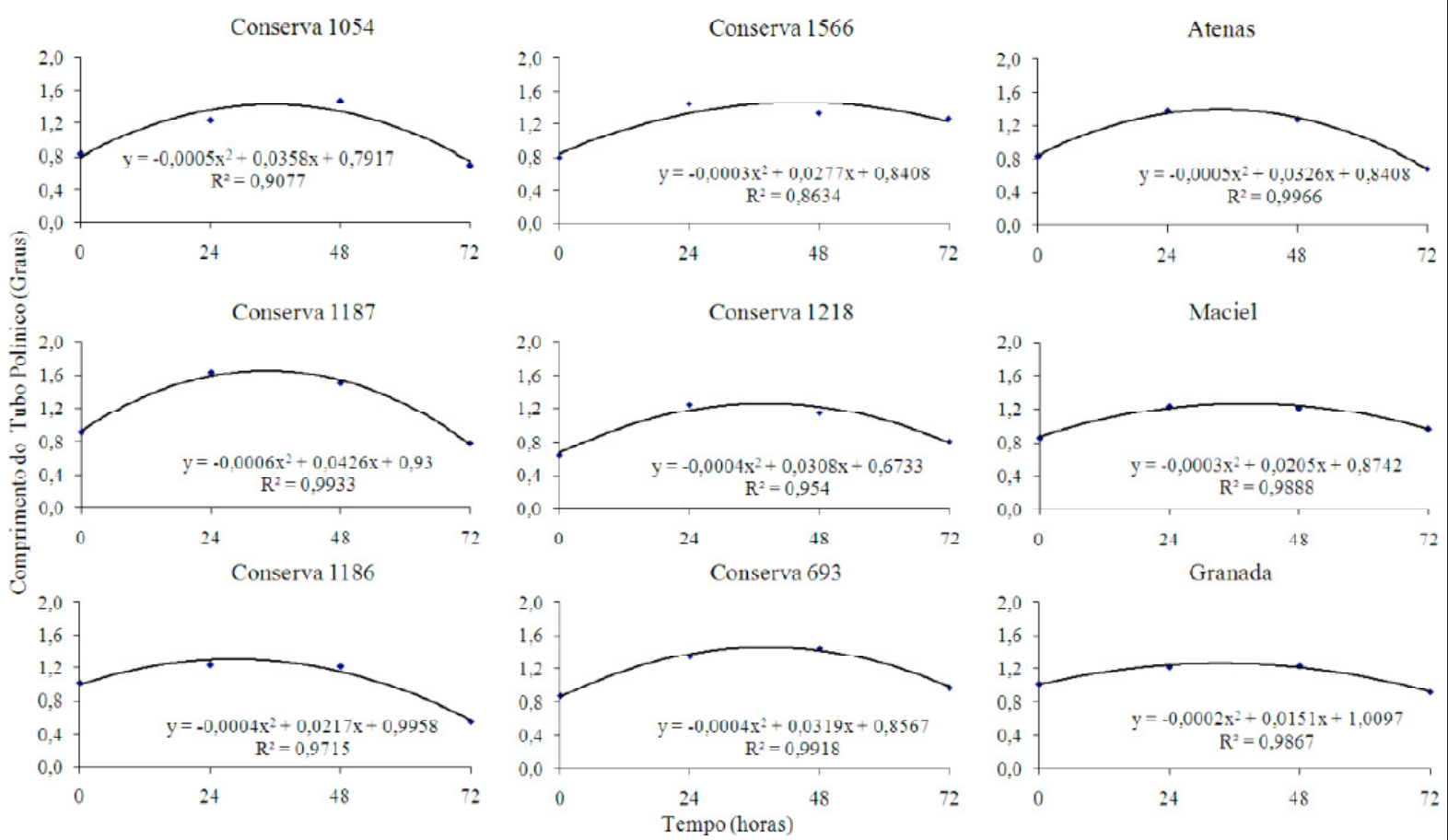

Figura 1 - Elongação do tubo polínico em flores de ramos destacados de pessegueiro ao longo do tempo decorrido após a emasculação em relação à temperatura (A) e aos genótipos estudados (B). Embrapa Clima Temperado, Pelotas, 2010.

Ciência Rural, v.41, n.12, dez, 2011. 
após a emasculação. CHAGAS et al. (2010) salientam que temperaturas elevadas proporcionam maior germinação de grãos de pólen de pereira (temperatura de $\left.28^{\circ} \mathrm{C}\right)$.

As cultivares 'Maciel', 'Granada', 'Conserva 1566', 'Conserva 1218' e 'Conserva 693' praticamente mantiveram similares elongamentos do tubo polínico, independente do tempo decorrido entre a emasculação e a polinização. Nos demais genótipos, houve uma notória queda nessa variável, após $48 \mathrm{~h}$ (Figura 1).

Com relação à receptividade do estigma, nos ramos destacados, houve interação tripla significativa $(\alpha=0,05)$ entre cultivar, temperatura e tempo. De maneira geral, o maior grau de receptividade do estigma ocorreu quando as flores foram polinizadas $48 \mathrm{~h}$ após a emasculação. Com relação à temperatura, a receptividade da maioria dos genótipos foi menor a $29^{\circ} \mathrm{C}$, com exceção das seleções Conserva 1566, Conserva 693 e da cv. 'Maciel'. Esses genótipos apresentaram valores $40 \%, 62 \%$ e $16 \%$ maiores nas flores polinizadas após $72 \mathrm{~h}$, sob $29^{\circ} \mathrm{C}$ que a $20^{\circ} \mathrm{C}$. A cv. 'Granada' apresentou maior elongação do tubo polínico, a $29^{\circ} \mathrm{C}$, quando a polinização foi realizada a zero, 24 ou 48 horas, mas caiu consideravelmente quando polinizada $72 \mathrm{~h}$ após emasculação. Isso leva a crer que esses podem ser materiais promissores para serem testados em locais com temperaturas mais elevadas (Figura 2).

Para a elongação do tubo polínico das flores avaliadas em plantas enxertadas, houve interação tripla significativa $\alpha=0,05)$ entre cultivar, tempo e temperatura. Em temperatura ambiente, 'Granada' e Conserva 693 tiveram melhor desenvolvimento do tubo polínico, se polinizadas $48 \mathrm{~h}$ após a emasculação, diminuindo em seguida, sendo essa redução mais acentuada na cv. 'Granada'. Já o desenvolvimento do tubo polínico na cv. 'Maciel' não foi influenciada pelo tempo. Quando as plantas foram submetidas a $29^{\circ} \mathrm{C}$, os três genótipos estudados tiveram melhor desenvolvimento do tubo polínico 48h após a emasculação, destacando aqui que 'Maciel' não foi afetado pela temperatura nem pelo tempo. 'Granada' e Conserva 693 tiveram menor desenvolvimento do tubo polínico $72 \mathrm{~h}$ após a emasculação, sendo que essa diminuição foi mais acentuada no Granada, que apresentou queda de $76 \%$ em relação à avaliação anterior (Figura 3).

Também para a receptividade do estigma de flores de plantas enxertadas de pessegueiro houve interação tripla significativa $(\alpha=0,05)$ entre cultivar, tempo e temperatura. O maior grau de receptividade nas plantas mantidas em temperatura ambiente ocorreu

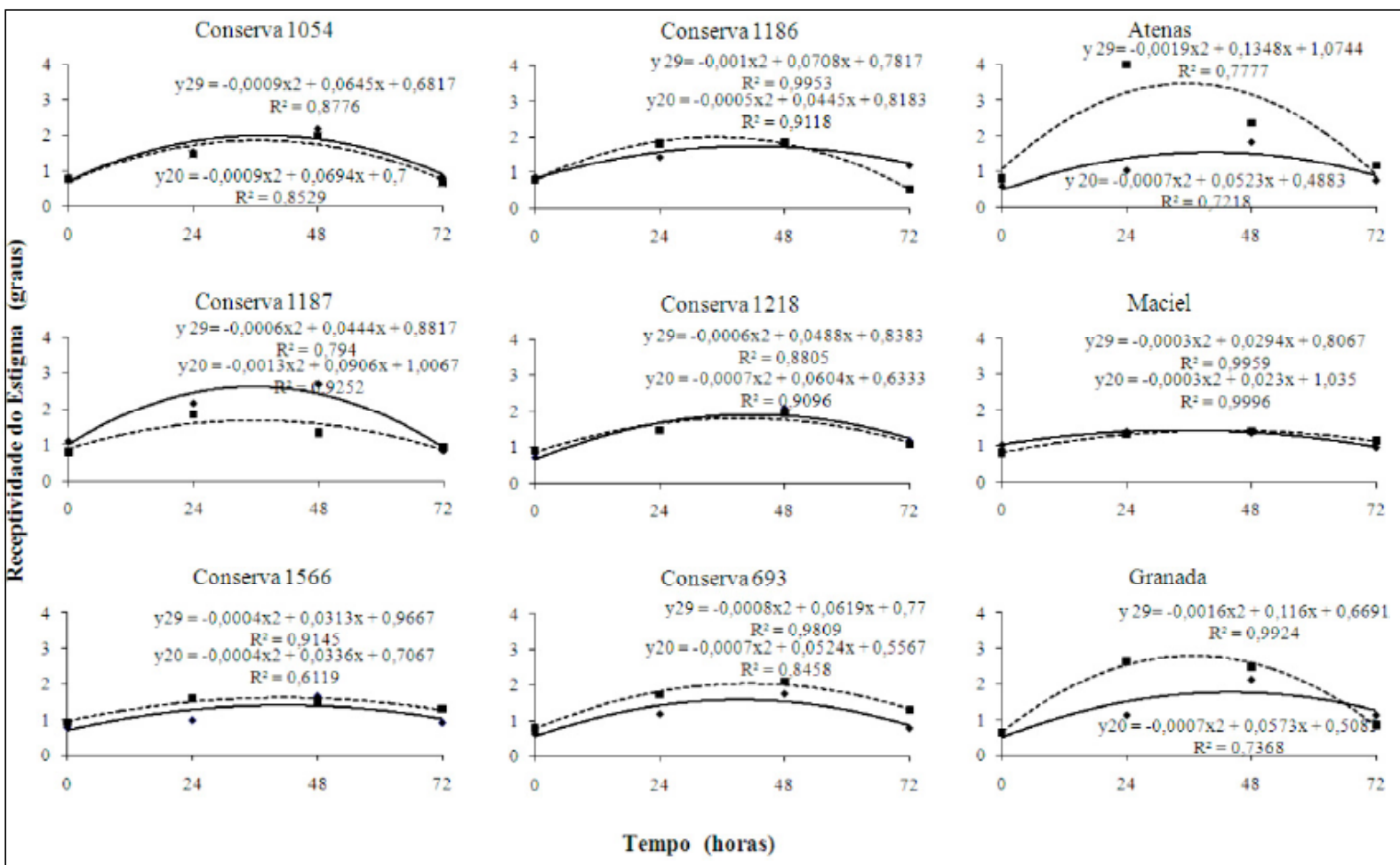

Figura 2 - Curvas de regressão para receptividade do estigma em flores de ramos destacados de pessegueiro, submetidas a $20^{\circ} \mathrm{C}$ e $29^{\circ} \mathrm{C}$. $(-) 20^{\circ} \mathrm{C},(-) 29^{\circ} \mathrm{C}$. Embrapa Clima Temperado, Pelotas, 2010. 


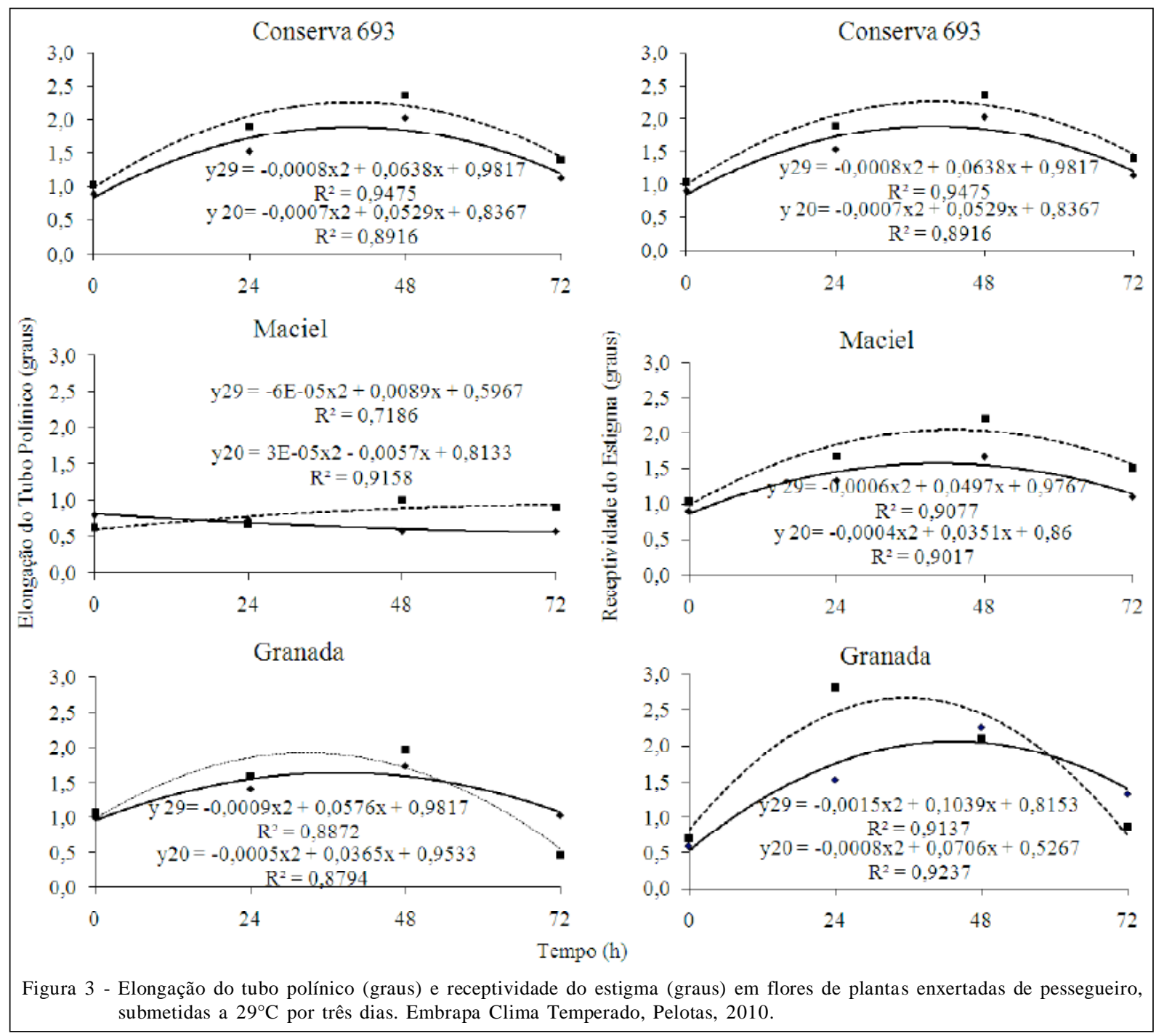

48h após a emasculação, diminuindo, em seguida, nos três genótipos avaliados. Quando as plantas foram submetidas à alta temperatura, o maior grau de receptividade na cv. 'Maciel' e na Conserva 693 também foi 48 h após a emasculação, diminuindo em seguida. Já para 'Granada', a receptividade foi maior 24h após a emasculação, diminuindo bruscamente após esse período (Figura 3).

Observou-se uma correlação significativa entre os resultados obtidos quando foram utilizados botões florais de ramos destacados ou plantas inteiras em vaso (enxertadas) para a receptividade do estigma (Tabela 2). Já para a elongação do tubo polínico não houve correlação significativa. Isso mostra que para estudo da receptividade do estigma é possível utilizar ramos destacados em vaso, com ganho em praticidade e espaço.
Informações sobre efeito da temperatura na pré-floração em espécies de Prunus são escassas e, por vezes, contraditórias. O período efetivo de polinização (PEP) tem sido um bom parâmetro para identificar fatores que limitam a frutificação de inúmeras espécies. Ele é definido como a longevidade do óvulo menos o tempo necessário para o tubo polínico alcançar o óvulo. Três são os principais fatores determinantes do PEP: receptividade do estigma, desenvolvimento do tubo polínico e longevidade do óvulo (SANZOL \& HERRERO, 2001).

Em pessegueiro, EREZ et al. (1998) observaram efeitos negativos das altas temperaturas durante a floração, sendo que temperaturas acima de $25^{\circ} \mathrm{C}$ durante o dia e acima de $18^{\circ} \mathrm{C}$ durante a noite diminuem consideravelmente a frutificação. Da mesma forma, NAVA et al. $(2009,2011)$ verificaram que, na 
Tabela 2 - Correlação entre ramos destacados e plantas enxertadas de pessegueiro, submetidos a $20^{\circ} \mathrm{C}$ e $29^{\circ} \mathrm{C}$ para receptividade do estigma. Embrapa Clima Temperado, Pelotas, 2010.

\begin{tabular}{|c|c|c|c|c|c|c|}
\hline & $\begin{array}{c}\text { Plantas } \\
\text { enxertadas / } 20^{\circ}\end{array}$ & $\begin{array}{c}\text { Plantas } \\
\text { enxertadas / } 29^{\circ}\end{array}$ & $\begin{array}{l}\text { Plantas } \\
\text { enxertadas }\end{array}$ & $\begin{array}{c}\text { Ramos } \\
\text { destacados } / 20^{\circ}\end{array}$ & $\begin{array}{c}\text { Ramos } \\
\text { destacados / } 29^{\circ}\end{array}$ & $\begin{array}{c}\text { Ramos } \\
\text { destacados }\end{array}$ \\
\hline $\begin{array}{l}\text { Plantas } \\
\text { enxertadas } / 20^{\circ}\end{array}$ & - & $0,77 * *$ & $0,93 * *$ & $0,65^{*}$ & $0,76^{* *}$ & $0.79 * *$ \\
\hline $\begin{array}{l}\text { Plantas } \\
\text { enxertadas } / 29^{\circ}\end{array}$ & - & - & $0,95^{* *}$ & 0,56 & $0,69^{*}$ & $0,66^{*}$ \\
\hline $\begin{array}{l}\text { Plantas } \\
\text { enxertadas }\end{array}$ & - & - & - & $0,64^{*}$ & $0,76^{* *}$ & $0,74 * *$ \\
\hline $\begin{array}{l}\text { Ramos } \\
\text { destacados } / 20^{\circ}\end{array}$ & - & - & - & - & $0,70 *$ & $0,95^{* *}$ \\
\hline $\begin{array}{l}\text { Ramos } \\
\text { destacados / } 29^{\circ}\end{array}$ & - & - & - & - & - & $0,89 * *$ \\
\hline $\begin{array}{l}\text { Ramos } \\
\text { destacados }\end{array}$ & - & - & - & - & - & - \\
\hline
\end{tabular}

* significativo a $5 \%$ de probabilidade

** significativo a $1 \%$ de probabilidade

cultivar 'Granada', altas temperaturas nos períodos de pré-floração e floração causam uma baixa viabilidade do pólen das flores e atraso no desenvolvimento dos óvulos, causando baixo desempenho reprodutivo, atuando negativamente sobre a frutificação efetiva das plantas.

No presente trabalho, as estimativas de graus de receptividade e de comprimento do tubo polínico nos ramos destacados sugerem que as seleções Conserva 1566 e Conserva 693 e a cv. 'Maciel' não sofreram negativamente influência da temperatura de $29^{\circ} \mathrm{C}$. Já a cv. 'Granada', embora com bons resultados quanto à elongação do tubo polínico, teve queda na receptividade do estigma entre 48 e $72 \mathrm{~h}$ após a emasculação.

Através dos resultados obtidos e a genealogia das seleções e cultivares testadas, podese verificar que as seleções Conserva 1186 e Conserva 1187 , que tiveram pior desempenho quando submetidas à temperatura de $29^{\circ} \mathrm{C}$, têm a cv. 'Granada' como parental, a qual também não teve bom desempenho.

Por outro lado, a cultivar 'Maciel', bem como as seleções Conserva 1566, Conserva 1218 e Conserva 693, que, pelos resultados obtidos até o presente indicam ter certa tolerância a altas temperaturas, têm como um dos ancestrais a cultivar 'Aldrighi', que provavelmente tenha genes para essa característica. Estes são genótipos de baixa necessidade em frio, adaptados a invernos amenos.

'Granada', que necessita maior acúmulo de frio hibernal do que os quatro genótipos comentados no parágrafo anterior, também tem a cultivar 'Aldrighi' como ancestral, mas foi cruzada com o material introduzido do programa de New Jersey, no ano de
1956, possivelmente com mais alta necessidade em frio que os introduzidos posteriormente, tornando-a pouco adaptada às regiões mais quentes do Sul do Brasil. A seleção Conserva 334, que também é um ancestral das seleções que tiveram melhor desempenho, foi também introduzida do programa de New Jersey, mas já é originária de programa de melhoramento visando a condições de inverno ameno.

Sugere-se um estudo futuro sobre uma possível correlação entre alta necessidade em frio e menor tolerância a temperaturas altas na floração.

\section{CONCLUSÃO}

As estimativas de graus de receptividade e de comprimento do tubo polínico nos ramos destacados sugerem que as seleções Conserva 1566 e Conserva 693 e a cv. 'Maciel' não sofreram negativamente influência da temperatura de $29^{\circ} \mathrm{C}$. De acordo com os resultados obtidos, a receptividade do estigma, mesmo em ramos destacados, pode discriminar os genótipos quanto à tolerância da parte feminina a temperaturas próximas a $29^{\circ} \mathrm{C}$.

\section{REFERÊNCIAS}

CARVALHO, T.C.P; RASEIRA, M.C.B. Período de floração e percentagem de frutificação efetiva em cultivares de ameixeira japonesa ( $P$. salicina, Lindl.) no Rio Grande do Sul. Pelotas: Embrapa Clima Temperado, 1989. 14p. (Boletim de Pesquisa, 16).

CHAGAS, E.A. et al. Composição do meio de cultura e condições ambientais para germinação de grãos de pólen de porta-enxertos de pereira. Ciência Rural, Santa Maria, v.40, n.2, p.231236, 2010. Disponível em: <http://www.scielo.br/ 
scielo.php?script $=$ sci_arttext \& pid=S $0103-$ $84782010000200002 \& \operatorname{lng}=p t \& n r m=i s o>$. Acesso em: 15 jun. 2011. doi: 10.1590/S0103-84782010000200002.

EREZ, A. et al. Greenhouse peach growing. Acta Horticulturae, Leuven, v.465, p.593-600, 1998. Disponível em: <http://www.actahort.org/members/showpdf?booknrarnr=465_74>. Acesso em: 22 ago. 2011.

HERTER, F.G. et al. Viabilidade da técnica de ramos enxertados para avaliar o efeito de indutores de brotação de pessegueiro. In: CONGRESSO BRASILEIRO DE FRUTICULTURA, 18., 2004, Florianópolis. Anais... Jaboticabal: Revista Brasileira de Fruticultura, 2004. CD-ROM.

KOZAI, N. et al. Adverse effects of high temperature on the development of reproductive organs in 'Hakuho' peach trees. Journal of Horticultural Science \& Biotechnology, Ashford, v.79, n.4, p.533-537, 2004.

NAVA, G.A. et al. Effect of high temperatures in the preblooming and blooming periods on ovule formation, pollen grains and yield of 'Granada' peach. Scientia Horticulturae, Amsterdam, v.122, p.37-44, 2009.

NAVA, G.A. et al. Desenvolvimento floral e produção de pessegueiros 'Granada' sob distintas condições climáticas. Revista Brasileira de Fruticultura, Jaboticabal, In Press, 2011. Disponível em: <http:/ /www.scielo.br/scielo.php?script=sci_arttext\&pid=S0100-
$29452011005000065 \& \operatorname{lng}=$ pt\&nrm=iso>. Acesso em: 22 ago. 2011. doi: $10.1590 / \mathrm{S} 0100-29452011005000065$.

PARK, B.H. et al. Temperature affect growth and flowering of the balloon flower [Platycodon grandiflorus (Jack) A.DC. cv. 'Astra Blue']. HortScience, Alexandria, v.33, n.2, p.233-236, 1998. Disponível em:<http://hortsci.ashspublications.org/cgi/reprint/33/2/ 233 ? maxtoshow $=\&$ hits $=10 \&$ RESULTFORMAT $=\&$ author $1=$ park $\&$ searchid $=1 \&$ FIRSTINDEX $=0 \&$ sortspec $=$ relevance $\&$ resourcetype $=$ HWCIT>. Acesso em: 22 ago. 2011.

RAMOS, J.D. et al. Stigma receptivity and in vitro citrus pollen grains germination protocol and adjustment. Interciencia, Caracas, v.33, n.1, p.51-55, 2008. Disponível em: <http://www.scielo.org.ve/ s cielo.php ? s cript=sci art text\&pid=S 0378 18442008000100011\&lng=en\&nrm=iso>. Acesso em: 22 ago. 2011.

RASEIRA, M.C.B.; NAKASU, B.H. Pessegueiro. In: BRUCKNER, C.H. (Ed.). Melhoramento de fruteiras de clima temperado. Viçosa: UFV, 2002. p.89-126.

SANZOL, J.; HERRERO, M. The "effective pollination period" in fruit trees. Scientia Horticulturae, Amsterdam, v.90, n.1, p.1-17, 2001.

WILSON, J.A.; BROWN, S.O. Differential staining of pollen tubes in Grass pistils. Agronomy Journal, Madison, v.49, n.4, p.220-222, 1957. Disponível em: <https://www.agronomy.org/ publications/aj/pdfs/49/4/AJ0490040220>. Acesso em: 22 ago. 2011. doi:10.2134/agronj1957.00021962004900040018x. 